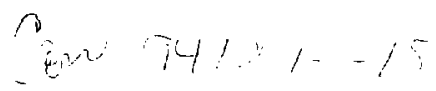

UCRL-JC-117325

PREPRINT .

\title{
Preparation of Germanium Doped Plasma Polymerized Coatings as ICF Target Ablators
}

\author{
R. M. Brusasco \\ M. D. Saculla \\ R. C. Cook
}

This paper was prepared for submittal to the 41st National Symposium of the American Vacuum Society

Denver, Colorado

October 24-28, 1994

October 5, 1994

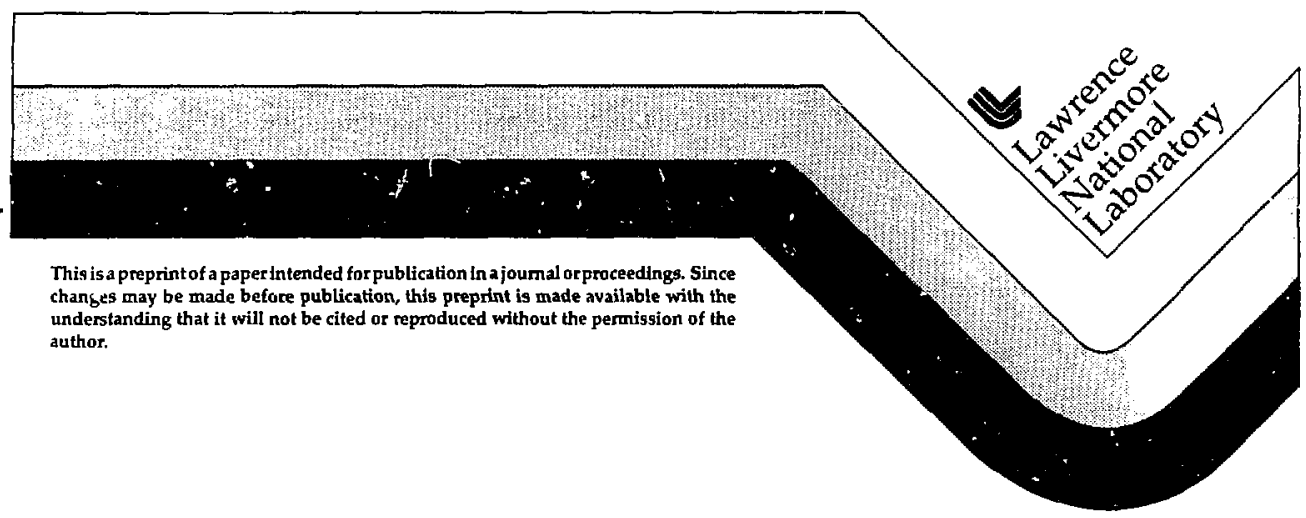




\section{DISCLATMER}

This document was prepared as an account of work sponsored by an agtncy of the United States Govemment. Neither the United States Government nor the University of Califomia nor any of their employees, makes any warranty, express or implied, or assumes any legal liability or responsibility for the accuracy. completeness, or usefulness of any information, apparatus, product, or process disclosed, or represents that its use would not iniringe privately owned rights. Reference herein to any specific commercial product, process, or service by trade name, mademark, manufackurer. or otherwise. does not necessarily constitute or impiy its endorsement, recommendation, or favoring by the linited States Government or the University of California. The views and opinions of authors expressed herein do not necessarily state or reflect those of the United States Government or the University of California, and shall not be used for advertising or product endorsement purposes. 
Preparation of Germanium Doped Plasma Polymerized

Coatings as ICF Target Ablators

Authors: Raymond Brusasco, Michael Saculla and Robert Cook

\begin{abstract}
Targets for Inertial Confinement Fusion (ICF) experiments at the Lawrence Livermore National Laboratory (LLNL) utilize an organic $(\mathrm{CH})$ ablator coating prepared by plasma polymerization. Some of these experiments require a mid- $Z$ dopant in the ablator coating to modify the opacity of the shell. Bromine had been used in the past, but the surface finish of brominated $\mathrm{CH}$ degrades rapidly with time upon exposure to air. This paper describes the preparation and characterization of plasma polymer layers containing germanium as a dopant at concentrations of between 1.25 and 2.25 atom percent. The coatings are stable in air and have an rms surface roughness of 7-9 nm (modes 10-1000) which is similar to that obtained with undoped coatings. High levels of dopant result in cracking of the inner mandrel during target assembly. Possible explanations for the observed cracking behavior will be discussed.
\end{abstract}




\section{INTRODUCTION}

Targets for use in Inertial Confinement Fusion (ICF) experiments at the Lawrence Livermore National Laboratory (LLNL) have multilayer configurations. The outermost layer, whose role is as an ablator to initiate compression of the target, is fabricated exclusively by plasma polymerization of organic precursors. In some implosion experiments it is necessary to control preheat in ignition capsules and the ablation front instability by doping the ablator layer with a small quantity of high $\mathrm{Z}$ material. ${ }^{1}$ Calculations have shown that germanium would make a good dopant in this regard. Irı addition to altering the composition of the ablator coating, careful attention must be paid to the surface roughness of the coating, as perturbations of the right size and shape can lead to Rayleigh-Taylor instabilities which subsequently degrade capsule performance. ${ }^{2}$ This paper will discuss the successful incorporation of germanium as a dopant in ablators prepared by plasma polymerization.

The recent literature contains several examples of the preparation of organogermanium films. $3,4,5$ Since our requirements are for very low doping concentrations (of the order of a few atom percent) our strategy is to co-react a germanium-bearing precursor with our standard poiymerization starting material, traris-2-butene (T2B) during ablator deposition.

\section{EXPERIMENTAL}

Coatings of germanium doped plasma polymer (CHGe) were prepared in a helical resonator plasma polymerization coater which has been in use at LLNL for many years. ${ }^{6}$ In our implementation of a helical resonator, a coil of wire surrounds a tapered silica reaction tube. RF energy is fed into a fixed tap on the coil and is impedance matched to the load via a $\pi$-type impedance matching network. The operating frequency is $43.5 \mathrm{MHz}$. Precursor gases of hydrogen and T2B flow down the tube and encounter a plasma in the tapered region. Figures 1 and 2 illustrate the design of the helical resonator coater.

\footnotetext{
${ }^{1}$ C.J. Keane, R.C. Cook, T.R. Dittrich, B.A. Hammel, W.K. Lev'edahl, O.L. Landen, S.H. Langer, D.H. Munro, and H.A. Scott, "Diagnosis of pusher-fuel mix in spherical implosions using x-ray spectroscopy", to be published in Reviez of Scientific Instruments.

2M.J. Dunning and S.W. Haan, "Analysis of Weakly Nonlinear Three-Dimensional Rayleigh-Taylor Instability Growth," in ICF Anmunl Report 1993, Lawrence Livermore National Laboratory, Livermort. CA, LCRI_-LR-105820-93 (1993), pp. 179-187.

${ }^{3}$ Gazicki, M., J. Schalko, F. Olcaytug, M. Ebel, H. Ebel, J. Wernisch and H. Yasuda, J. V 1c. Sci. Tech. A, 12(2) 345, 1994.

"Tyczkow'ski, J., P. Kazımierski and H. Szymanow'ski, Thun Solict Films, 241 291, 1'm,3.

5 Sadhir, R.K., H.E. Saunders and W.A. Byers, Polym. Eng. Sci., 13(10) 645, 1993.

GJohnson, W.L., S.A. Letts, C.W. Hatcher, L.E. Lorensen and C.D. Hendricks, ACS Symp. Ser. No. 10s, Plasma Polymerization, 315, 1979.
} 


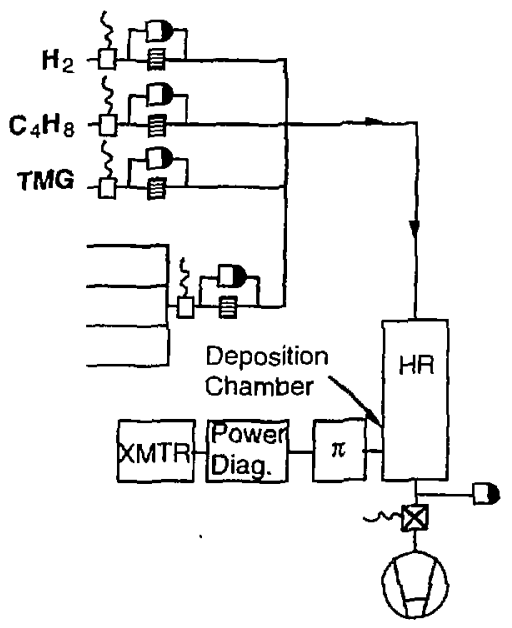

Figure 1.

Schematic diagram of the helical resonator plasma polymerization device (overall construction and flow system). 


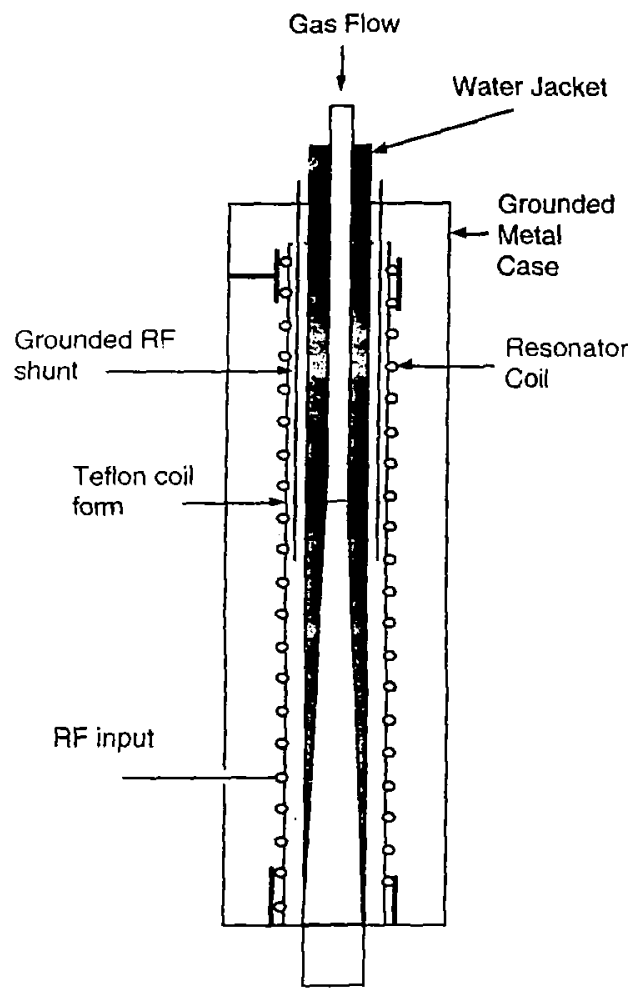

Figure 2. Schematic diagram of the helical resonator plasma applicator.

Doring of the plasma polymer with germanium is achieved by adding a small amount of tetramethylgermane (TMG) vapor to the gas flow. Depending upon the germanium level desired, the flow rate of TMG varies between 0.074 and $0.144 \mathrm{sccm}$. Table I lists the constant operating parameters of the coater.

Substrates used in this work consisted of spherical target mandrels, silicon wafer substrates and thin fused silica disks. Target mandrels are formed from spherical shells of polystyrene approximately $410 \mu \mathrm{m}$ in diameter and $2-3 \mu \mathrm{m}$ in thickness. These shells are overcoated with $2-3 \mu \mathrm{m}$ of polyvinyl alcohol, then placed in the piasma polymerization coater. Silicon wafers are $1 \mathrm{~cm}^{2}$ square and are precleaned 
before deposition using $\mathrm{CO}_{2}$ "snow" as a cleaning agent." $\mathrm{A}$ wafer is placed on a 5 $\mathrm{cm} X 8 \mathrm{~cm}$ glass microscope slide when loaded into the deposition chamber. Fused silica disks, $25.4 \mathrm{~mm}$ in diameter and $400 \mu \mathrm{m}$ thick, are used as substrates in the qualitative determination of residual coating stress. They are first coated on one side with approximately $2000 \AA$ of aluminum as a reflector; the other side is then coated with plasma polymer to a thickness of $1.7 \mu \mathrm{m}$.

Coating thickness on spheres is measured using interferometry. Thickness determinations on flat substrates are performed using a Tencor stylus profilometer. Roughness measurements on spheres are made using a circumferentially scanning atomic force microscope (AFM) technique. ${ }^{3}$ The roughness power spectrum is computed using the height versus azimuthal angle data for each trace in the AFM scan and then averaging the spectra.

The determination of germanium content is accomplished using an $X$-ray microfluorescence mathod. ${ }^{9}$ A brief description of the technique is given here. Glass slides coated with $\mathrm{CHGe}$ are analyzed for $\mathrm{X}$-ray emission from germanium in the polymer and trace amounts of calcium in the glass using a Kevex Omicron $X$-ray microfluorescence analyzer. The calcium emission is attenuated by the hydrocarbon matrix and germanium atoms. The thickness at the point of analysis is measured. The degree of $\mathrm{Ca}$ absorption from the hydrocarbon matrix is calculated from the thickness of the coating and the known density of plain plasma polymer. Additional $\mathrm{Ca} X$-ray attenuation is ascribed completely to germanium. The concentration of germanium is determined utilizing the mass absorption coefficient and assuming a uniform distribution of $G$ which is assumed to simply replace $C$ in the polymer matrix. When several different samples are analyzed, a calibration curve of germanium $X$-ray counts versus germanium concentration (via $\mathrm{Ca} X$-ray attenuation) is generated which is then applied in the determination of germanium in target mandrels. An estimate of the error in germanium concentration by this method is $\approx 5 \%$ of the concentration value obtained.

The density of one sample of CHGe was determined by forming a shape controlled deposit on a pre-weighed silicon wafer. The wafer was weighed again just after the deposition using a Cahn microbalance with $1 \mu \mathrm{g}$ precision. The shape of the deposit was then analyzed to obtain the volume.

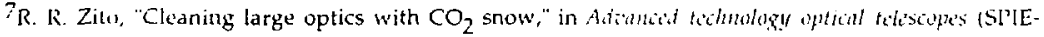
The International Society of Photo-Optical Instrumentation Enginess, Bellingh.m, WA, 1wo(); Pris. SPIE 1236) pp. 452.

SR.L. MeEathern, C.E. Moore and R.J. Wallace, "The Desight. Performance and Application of an Atomk" Force Microscople-Based I'rufilometer," this proceeding.

${ }^{9}$ R.C. Cook, T.P. Bernat, G. Collins, S.A. Letts, R. MacEachern, G.E. Overturi and R.E. Turner, "production and characterization of ICF capsules," in Plasma fluysts and combrollid nucken fusion resiarly 7992 Vol 3, p 449-454 (1993).
} 
Qualitative measurements of residual stress in coatings were made by measuring the deformation of a fused silica stress disk coated with plasma polymer using a Zygo interferometer. A greater deformation at constant coating thickness is a qualitative indicator of greater residual coating stress after deposition.

The deformation of the stress disk results in the formation of a concave, rather than planar, substrate. Assuming the substrate is bent into a segment of a sphere, the distortion can be quantified by calculating the radius of curvature via equation 1 ,

$$
R=\frac{S}{2 \pi h}
$$

where $S$ is the surface area of the disk (a constant) and $h$ is the height of the segment found by interferometry.

\section{RESULTS AND DISCUSSION}

\section{Deposition rate and surface roughness}

Germanium doping levals of approximately 1.25 and 2.25 atom percent have been utilized in the Hydrodynamically Equivalent Physics (HEP) experimental program at LLNL. Figure 3 plots the repeatability, in both deposition rate and germaniurn content, for identical runs in the two germanium concentration regimes. The reproducibility is very good.

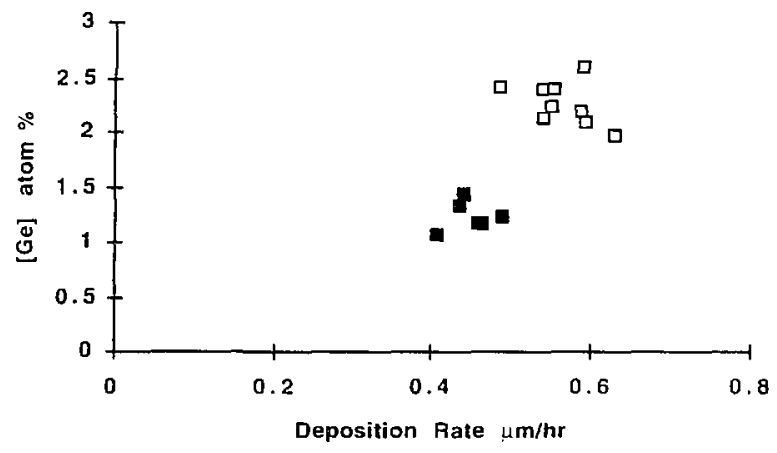

Figure 3. Plot of the germanium content and deposition rate for several identical experiments preparing 1.25 
atom percent (filled symbols) and 2.5 atom percent (open symbols) doped plasma polymer on target mandrels. The reproducibility on shells is very good.

The deposition rate varies between $0.45 \mu \mathrm{m} \mathrm{hr}^{-1}$ at 1.25 atom percent germanium and up to $0.56 \mu \mathrm{ma} \mathrm{hr}{ }^{-1}$ when the TMG flow rate is increased to provide 2.25 atom percent doping. Presumably at least part of the increased deposition rate is due to the additional carbon introduced into the system by virtue of the organic ligands on the germanium precursor, however a detailed deposition mechanism is as yet unknown.

Figure 4 plots the roughness power in $\mathrm{nm}^{2}$ versus mode frequency obtained for typical plasma polymer coatings on target spheres. The gray line shows the result for plain, undoped plasma polymer and the black line represents plasma polymer doped with germanium. It can be seen that the surface roughness of the two are very similar, with rms roughness values typically in the range of 7 to $9 \mathrm{~nm}$ when computed from mode 10 to mode 1000.

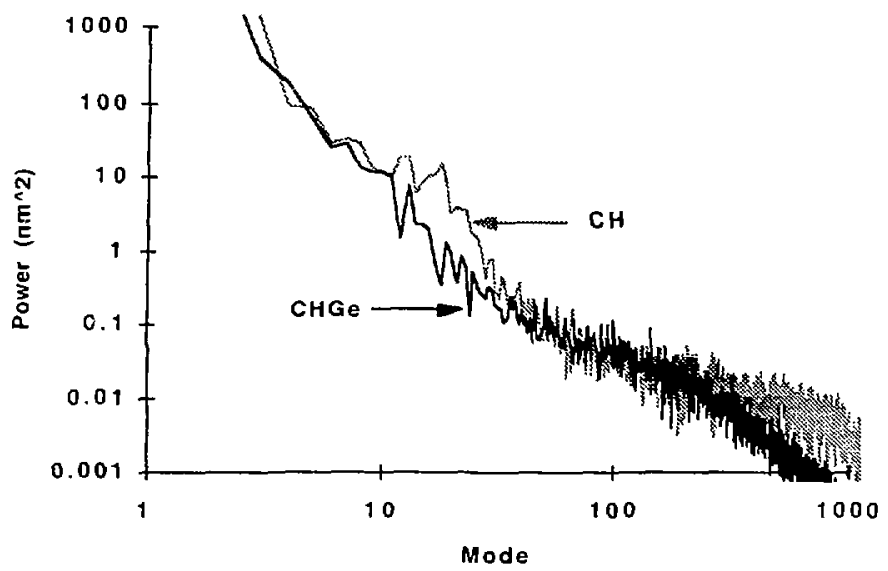

Figure 4. Plot of the power spectra for plain, undoped plasma polymer ( gray line) and germanium doped plasmia polymer ( black line) on spherical mandrels. 
Previous to this time, bromine had been used as an ablator dopant. ${ }^{9}$ This material suffered from an aging mechanism which caused the surface to roughen over time. An investigation into the nature of this phenomenon revealed that the cause was due to the crystallization of $\mathrm{NH}_{4} \mathrm{Br}$ from the polymer matrix. ${ }^{10}$ Figure 5 plots the rms roughness of bromine and germanium doped plasma polymer versus time after completion of the coating in days. In comparison to the bromine seeded materiai, germanium doped plasma polymer shows no significant tendency to roughen over long periods of time.

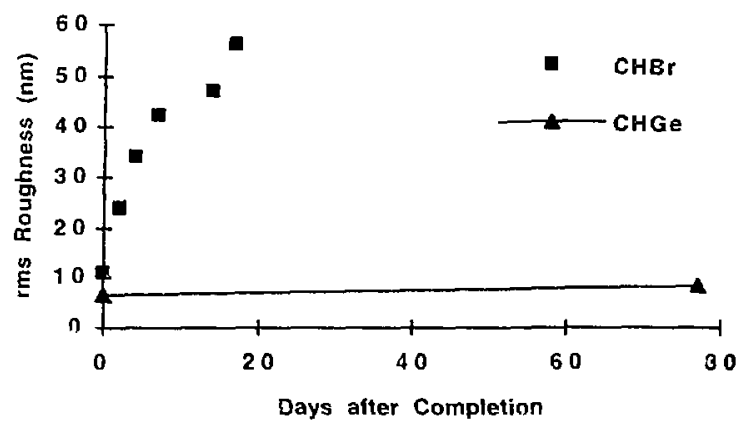

Figure 5. Plot of the rms roughness versus time atter completion for bromine seeded (squares) and germanium seeded itriangles; plasma polymer coatings.

\section{Density determination}

The determination of density proceeded from a straightforward analysis of the weight and shape of a small amount of germanium doped plasma polymer. The weight of a microdot of $\mathrm{CHGe}$ (doped to 2.8 atom percent) deposited on a preweighed silicon wafer was determined by difference. The shape of the deposit was determined by taking four thickness scans across the dot diameter separated by $45^{\circ}$ using the Tencor stylus profilometer. Figure 6 plots the results of the four thickness traces. The thin lines are the individual traces and the thick line represents the average of the eight radial traces. The height data was taken at $5 \mu \mathrm{m}$ intervals, thus the slightly greater than 5000 micron width represents 1015 measurements.

10 S.A. Leits, R.C. Cook, P. Welch, R. McEachern and E. Fearm, 205!h American Chemical soirety National Meeting, Derver, CO, Report CONF-930314, p 323, 1993. 


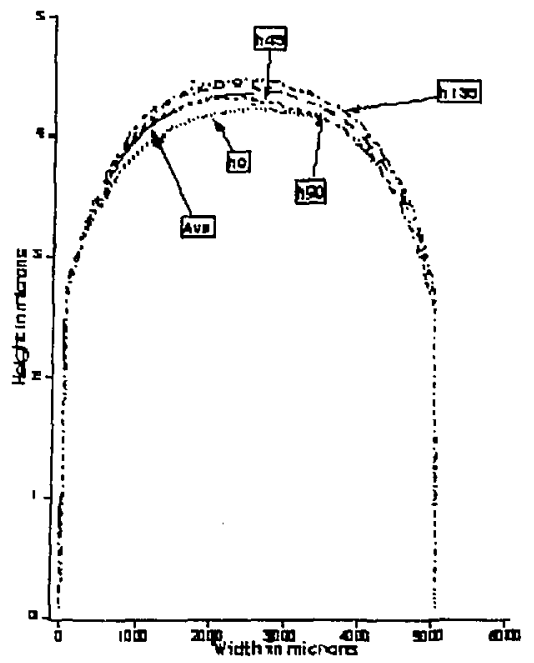

Figure 6. Plot of the height versus width of a specimen of CHGe used in determination of the density.

With 1015 data points, the center of the dot is at data point 508. The average height as a function of distance from the center is calculated by,

$$
h_{\text {ive }}\left(r_{i}\right)=\frac{1}{t} \sum_{\text {trace } 1}\left(h_{l}\left(r_{i}\right)+h_{t}\left(r_{1016-i}\right)\right) / 2
$$

The volume of the specimen is then calculated as,

$$
V=\sum_{i=1}^{50 \pi}\left(\pi r_{i+1}^{2}-\pi r_{i}^{2}\right)\left(h_{\mathrm{sue}}\left(r_{i+1}\right)+h_{\mathrm{ive}}\left(r_{i}\right)\right) / 2
$$

where the index $i$ now counts out from the center of the dot. From this we determined the solume to be $7.30 \times 10^{-5} \mathrm{~cm}^{3}$. The weight of the specimen was determined to be $93.2 \mu \mathrm{gram}$ ( $1 \%$ error). Thus, the density of the specinen becomes $1.227 \mathrm{~g} \mathrm{~cm}^{-3}$. This value compares favorably with the plot of density versus germanium content in the paper by Gazicki, et al. ${ }^{3}$

Cracking and stress 
One troubling feature of preparing ablators with germanium disping lies in an increased propensity for finished target mandrels to crack dis: . takes place after ablator fabrication. It has been observed generally that cracis cccur only in the inner polystyrene layer of the mandrel, that the cracks never propagate through the polyvinyl alcohol diffusion barriex layer ${ }^{11}$ and that cracking is mosi likely to occur in a post-deposition step that expuses the shell to an as, itimetric thermal gradient. We have found that the striousness of the cracking problem is a function of the germanium concentration in the plasma polymer; nore germanium incorporation results in more cracking. The composition c.t the polystyrene inner mandrel magnifies the tendency to crack, i.e. When the polystyrene is doped with titaniu!m for spectroscopic measurements during a target implosion, the cracking problem becomes more severe $t=$ ? $n$ that for a plain polystyrent mandre:

There are miny possible explanations for such behavior, ranging from undesirabla thermomechanical properties of the ablator to residual stress after coating. To begiat addressing this issue, qualitative measurements of residual coating stress were made. We find that the radius of curvature for siress disks varies from $500 \mathrm{~m}$ for plain plasma polymer down to a value of $100 \mathrm{~m}$ at the highest incorporation levels. The absolute vaiues of the stress have no: beerı determined and the precise. relationship between residual stressi and cracking behavior has not been investigated. Some techniques described ir. the literature $12,13,14$ may te useful for quanitation, but the applicability of thesis techniques to our system has not been dene. More work in this area is called for. Current efforts are focussed on preparing ablator coatings with the minimum amount of germanium needed and increasing the robustness of the inner polystyrene mandrel when doped for spertroscopic purposes.

\section{CONCLUSIONS}

It has been es:-iblished that small amounts of germanium can be reproducibly incorporated into plasma polymer coatings. The coatings have been deposited to thicknesses of $45 \mu \mathrm{m}$ ivith surface roughness of 7 to $9 \mathrm{~nm}$ rms or spherical substrates. The coating rates generally are 0.45 to $0.56 \mu \mathrm{m} \mathrm{hr}$. The ciensity of the coating doped to a level of 2 atom percent is $1.23 \mathrm{~g} \mathrm{~cm}^{-3}$. and is in agleement with density values for similar coatings reported in the literature. Theae have been problems with shell cracking, with increasing amounts of germanium and pusher dopants exacerbate the problem.

\section{ACKNOWLEDGMENTS}

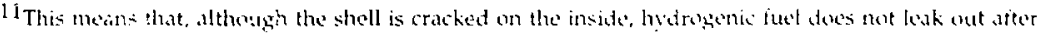
fill.

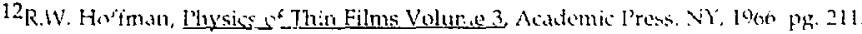

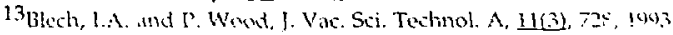

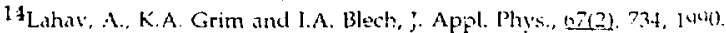


The authors gratefully acknowledge the technical assistance of Anselmo Dueñas, Craig Moore, Rand McEachern, Evelyn Fearon, Bob Turner, Leslie Allison and Charlotte King. Work performed under the auspices of the U.S. Department of Energy by Lawrence Livermore National Laboratory under Contract W-7405-ENG48. 


\section{TABLE I}

Operating parameters for the helical resonator coater

Ii flow rate

T2B flow rate

Total pressure

RF power
$13 \mathrm{sccm}$

$0.3 \mathrm{sccm}$

$70 \mathrm{mTorr}$

$12 \mathrm{~W}$ 